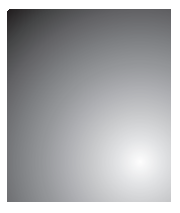

\title{
Competitividade de Mercado e Gerenciamento de Resultados: Um Estudo sob a ótica da Teoria da Contingência
}

\author{
Mercat competitivity and result management: \\ A study under the optic of the contingency teory
}

\author{
Geovanne Dias de Moura \\ Doutor em Ciências Contábeis e Administração. Professor do Mestrado em Ciências Contábeis e Administração da \\ Universidade Comunitária da Região de Chapecó - UNOCHAPECÓ. Chapecó, SC. Brasil. E-mail: geomoura@terra.com.br
}

\section{Tiago Francisco de Camargo}

Mestrando em Ciências Contábeis e Administração pela Universidade Comunitária da Região de Chapecó - UNOCHAPECÓ.

Chapecó, SC. Brasil. E-mail: tiago.camargo@unochapeco.edu.br

\section{Antonio Zanin}

Doutor em Engenharia de Produção pela Universidade Federal do Rio Grande do Sul - UFRGS. Professor do Mestrado em Ciências Contábeis e Administração da Universidade Comunitária da Região de Chapecó - UNOCHAPECÓ. Chapecó, SC. Brasil.

E-mail: zanin@unochapeco.edu.br

\section{Resumo}

O estudo objetiva verificar a influência da competitividade de mercado no gerenciamento de resultados das companhias abertas listadas na B3, sob a ótica da Teoria da Contingência. Realizou-se pesquisa descritiva, documental e quantitativa. A amostra da pesquisa foi composta por 277 companhias em 2010, 284 em 2011, 288 em 2012, 289 em 2013 e 287 em 2014. Os dados foram obtidos por meio do banco de dados Economática. Como proxy para competitividade, foi utilizado o índice de Herfindahl-Hirschman (HHI). O gerenciamento de resultados foi analisado por meio dos accruals discricionários baseados no modelo Jones Modificado (DECHOW; SLOAN; SWEENEY, 1995). Os resultados revelaram que no setor econômico de petróleo, gás e biocombustíveis havia ocorrência de um monopólio, nos setores de tecnologia da informação e de telecomunicações os índices indicaram oligopólios e nos demais setores apontaram para uma estrutura de concorrência perfeita. Quanto ao gerenciamento de resultados, constatou-se que a maioria das empresas realizaram gerenciamentos de baixas proporções. Por fim, os resultados evidenciaram uma relação não significativa entre competitividade e gerenciamento de resultados. Portanto, não se pode afirmar que a competitividade é um fator contingencial que influencia na prática do gerenciamento de resultados.

Palavras-chave: Competitividade de mercado. Gerenciamento de resultados. Teoria da Contingência.

\section{Abstract}

The objective of this study is to verify the influence of market competitiveness on the earnings management of listed companies listed on the $\mathrm{B} 3$, under the perspective of Contingency Theory. Descriptive, documentary and quantitative research was carried out. The survey sample consisted of 277 companies in 2010, 284 in 2011, 288 in 2012, 289 in 2013 and 287 in 2014 . The data were obtained through the Economática database. The Herfindahl-Hirschman Index (HHI) was used as a proxy for competitiveness. Earnings management was analyzed using the Modified Jones model (DECHOW; SLOAN; SWEENEY, 1995). The results showed that in the oil, gas and biofuels economic sectors there was a monopoly, in the sectors of information technology and telecommunications the indexes indicated oligopolies and in the other sectors pointed to a perfect competition structure. Regarding earnings management, it was verified that the majority of the companies carried out management of low proportions. Finally, the results showed a non-significant relationship between competitiveness and earnings management. Therefore, it cannot be said that competitiveness is a contingency factor that influences the practice of earnings management.

Keywords: Market competitiveness. Earnings management. Contingency Theory. 


\section{INTRODUÇÃo}

O ambiente institucional de um país é constituído por um conjunto de regras, tanto políticas quanto sociais, que consolidam a base para a produção, troca e distribuição dentro de um sistema (CHAKRABARTY, 2009; SAHAYM; NAM, 2013). Quando o mercado acionário é ativo, quando fornece maior proteção aos investidores e quando as empresas enfrentam uma competitividade de mercado mais acirrada em termos de produtos e de fatores de capital e trabalho, o ambiente institucional pode ser considerado forte (WEI et al., 2011).

Por outro lado, um ambiente institucional considerado frágil caracteriza-se por um mercado acionário menos ativo e com uma proteção legal aos direitos de propriedade significativamente inferiores (MORCK; STANGELAND; YEUNG, 2000; BALL; ROBIN; WU, 2003; FEITO-RUIZ; MENÉNDEZ-REQUEIJO, 2010). Feito-Ruiz e Menédez-Requejo (2010) mencionam que nesse tipo de ambiente é comum ter companhias com propriedade altamente concentrada, baixa captação de recursos em mercado de ações, além de sistemas de governança deficientes.

De modo geral, em um ambiente institucional fraco, um conjunto de fatores contribuem para fragilizar o ambiente, causar falhas no mercado e abrir brechas para o comportamento oportunista de gestores, aumentando, inclusive, a possibilidade da prática de gerenciamento de resultados (DYCK; ZINGALES, 2004; LIAO, LIN, 2016). O gerenciamento de resultados é um conjunto de práticas ou escolhas contábeis adotadas pelos gestores com objetivo de alterar informações contábeis ou gerar resultados desejáveis (PAULO, 2007; REZENDE; NAKAO, 2012).

Ressalta-se que ainda não há uma teoria específica que trate do gerenciamento de resultados, o que existem são estudos que identificam situações nas quais os gestores o praticam. Então, entender as possíveis práticas de gerenciamento que podem ser amparadas dentro das lacunas da legislação, o ambiente de incertezas e de subjetividades ao qual o sistema empresa está inserido, representa um fértil campo para investigações (ROSA; TIRAS, 2013).

Nesse contexto, a competitividade pode ser um fator contingencial que influenciará na prática do gerenciamento de resultados, pois, gestores de empresas situadas em ambientes com maior nível de competitividade estarão em um cenário menos propício para práticas oportunistas, haja vista que a competitividade pode exercer um efeito disciplinador (ALMEIDA, 2010; LAKSMANA; YANG, 2014; LIAO, LIN, 2016).

Portanto, a Teoria da Contingência, que traz em seu escopo o pressuposto de que as organizações sofrem influências do ambiente onde estão inseridas, conforme descreve Donaldson (1999), pode auxiliar na análise da relação entre competitividade e gerenciamento de resultados. Sob este aspecto Lacombe e Heilborn (2003, p. 428) esclarecem que "[...] a Teoria da Contingência parte da premissa básica de que as condições do ambiente é que causam as transformações no interior das organizações".

Assim, surge a pergunta de pesquisa que orienta este estudo: qual é a influência da competitividade de mercado no gerenciamento de resultados das companhias abertas listadas na B3? Portanto, o estudo objetiva verificar a influência da competitividade de mercado no gerenciamento de resultados das companhias abertas listadas na B3, sob a ótica da Teoria da Contingência.

Ressalta-se que a maioria das pesquisas empíricas realizadas sobre gerenciamento de resultados associam a sua prática a fatores como, por exemplo, adoção de normas internacionais de contabilidade (GRECCO, 2013; ROSA; TIRAS, 2013; CARDOSO; SOUZA; DANTAS, 2015; SILVA; FONSECA, 2015; LO, RAMOS; ROGO, 2017), governança corporativa (MARTINEZ, 2011; ERFURTH; BEZERRA, 2013; PICCOLI; SOUZA; SILVA, 2014; CHI et al., 2015; MAZZIONI et al., 2015; XUE; HONG, 2016), auditoria (DEBOSKEY; JIANG, 2011; MARTINEZ, 2011; CUNHA et al., 2014; SILVA et al., 2014; PERSAKIS; IATRIDIS, 2016), estrutura de propriedade (CHI et al., 2015; KAZEMIAN; SANUSI, 2015; RAZZAQUE; ALI; MATHER, 2016; BAO; LEWELLYN, 2017; SHAYAN-NIA et al., 2017), estrutura de capital (RODRÍGUEZ-PÉREZ; HEMMEN, 2010; FUNG; GOODWIN, 2013; BARROS et al., 2014; MAZZIONI et al., 2015; AN; LI; YU, 2016), investidores institucionais (HADANI; GORANOVA; KHAN, 2011; DAI; KONG; WANG, 2013; KIM et al., 2016; LO; WU, KWEH, 2017), custo de capital (KIM; SOHN, 2013; CRABTREE; MAHER; WAN, 2014; MOURA et al., 2016; PERSAKIS; IATRIDIS, 2016; GHOUMA, 2017).

Portanto, a relevância do estudo está no fato dele buscar relacionar a prática do gerenciamento de 
resultados com a competitividade de mercado, um fator ainda pouco explorado, principalmente na literatura nacional. Além disso, pesquisas existentes que investigaram tal associação apresentaram resultados divergentes. Enquanto Laksmana e Yang (2014) e Liao e Lin (2016), por exemplo, constaram que a competitividade influenciava para um menor gerenciamento de resultados em companhias americanas, Almeida (2010) não encontrou associação para uma amostra constituída por companhias brasileiras, assim como Kordestani e Mohammadi (2016) também não identificaram associação entre competitividade e gerenciamento em uma amostra de companhias iranianas.

Sendo assim, o estudo justifica-se, também, em razão das divergências constatadas em resultados de pesquisas anteriores de mesma natureza e que geram inquietações. Nesse sentido, Bao e Lewellyn (2017) destacam que, de um modo geral, a compreensão $e$ as evidências empíricas de fatores que influenciam no gerenciamento de resultados em países emergentes ainda são reduzidas. Portanto, o estudo contribui para esta lacuna de pesquisa constatada na revisão da literatura. Procura, ainda, fortalecer o entendimento sobre o tema no cenário brasileiro e estende a discussão relacionada aos fatores que podem influenciar na prática do gerenciamento de resultados.

\section{Referencial Teórico}

Nesta seção apresenta-se o referencial teórico, que servirá de sustentação para o desenvolvimento do estudo empírico. Inicia-se com definições sobre a Teoria da Contingência. Na sequência, trata-se sobre a competitividade de mercado como fator contingencial para o gerenciamento de resultados. Por fim, aborda-se, de modo mais específico, sobre o gerenciamento de resultados.

\subsection{Teoria da Contingência}

As Teorias Neoclássicas da administração continuam exercendo grande influência na literatura e em áreas como a contabilidade, por exemplo. Para Burns e Scapens (2000). diversos pesquisadores de contabilidade gerencial fundamentam-se em pressupostos da Teoria Neoclássica. Também estão presentes os princípios gerais de administração da Teoria Clássica, possíveis de serem percebidos na composição do orçamento empresarial (GUERRA, 2007).

De acordo com Bateman e Snell, (1998), percebe-se que as teorias vieram para complementar umas às outras, mesmo porque o surgimento de uma, ocorre em função de críticas atribuídas a outra. Assim, as teorias evoluem, tentando explicar os GAAPs que existem na complexidade das pesquisas sociais aplicadas. No campo da contabilidade, uma abordagem que ganhou destaque foi a sistêmica, que explica como as organizações deveriam se relacionar com o ambiente interno e externo.

Foi a abordagem sistêmica que influenciou fortemente o surgimento da Teoria da Contingência, principalmente a partir do final da década de 1950, quando pesquisadores passaram a investigar os processos estruturais das organizações, sob uma visão sistêmica, levando em consideração o ambiente externo ao qual as organizações estavam inseridas. Nesta época, apareceram pesquisas clássicas na literatura internacional, tais como Burns e Stalker (1961), Chandler (1962) e Woodward (1965), que buscavam identificar como variáveis contingencias (por exemplo: ambiente, tecnologia e a estratégia) impactavam nos resultados e na estrutura das empresas. Destaca-se que estes estudos são considerados precursores da Teoria da Contingência (GUERRA, 2007).

$\mathrm{Na}$ abordagem contingencial, de acordo com Guerra (2007), os fatores situacionais, encontrados tanto no ambiente interno, quanto no externo, precisam ser levados em consideração. No ambiente externo são representados por variáveis independentes, sob as quais a empresa não exerce controle algum, caso da tecnologia. Por outro lado, no ambiente interno, são fatores que representam variáveis dependentes, tais como a estratégia, estrutura, o tamanho, cultura, ou seja, fatores sob os quais a empresa exerce o controle.

Ressalta-se que a Teoria da Contingência possui o pressuposto de que as organizações recebem influências do ambiente onde estão inseridas, ou seja, sofrem impactos advindos do ambiente externo em que operam. Por consequência, ocorrem alterações internas, como na estrutura, no tamanho e na estratégia. Deste modo, o ambiente pode contribuir para remodelar características específicas da empresa em determinado momento (JUNQUEIRA, 2010). 
Nesse sentido, a Teoria da Contingência, conforme descrito por Donaldson (1999, p. 105), "[...] estabelece que não há uma estrutura organizacional única que seja altamente efetiva para todas as organizações". Para o autor, o arranjo ideal dos fatores dependerá do momento e do ambiente em que a empresa está inserida, podendo ser alterados devido a questóes que não podem ser controladas internamente.

Deste modo, a otimização da estrutura (hierarquização, setores, processos, pessoas, etc.), estratégia (ações, decisões, etc.) e tecnologia (máquinas, equipamentos diversos, softwares, etc.) podem variar em razão de inúmeros fatores, como por exemplo, a globalização, regulamentações, surgimento de novas tecnologias, competitividade de mercado, entre outros.

Ressalta-se que entre as variáveis que não podem ser controladas pela empresa, encontra-se a competitividade de mercado, entendida, nesta pesquisa, como um fator contingencial para o gerenciamento de resultados.

\subsection{Competitividade como fator contingencial para o gerenciamento de resultados}

O nível de competitividade pode influenciar nas decisões de gestores, como por exemplo, praticar ou não gerenciamento de resultados (DHALIWAL et al., 2008; ALMEIDA, 2010). Isso ocorre porque a competição fornece incentivos para que os gestores aprimorem suas ferramentas de gestão e, também, mantenham internamente um conjunto de recursos que se integrem com o objetivo de possibilitar maior desenvolvimento e uma melhoria contínua. Nesse sentido, a competição é descrita por Laksmana e Yang (2014) e Liao e Lin (2016) como disciplinadora da discricionariedade das ações e das decisões dos executivos.

Todavia, os estudos que relacionam questões envolvendo propriedades da contabilidade e competitividade ainda são reduzidos na literatura (ALMEIDA, 2010). Como exemplos de estudos que investigaram e constataram que a competitividade pode provocar alterações no ambiente interno das empresas podem ser citados os de Moura, Mecking e Scarpin (2013), Sobrinho et al. (2014), Moura e Klann (2016) e, mais especificamente relacionados ao tema desta pesquisa, Laksmana e Yang (2014) e Liao e Lin (2016).
Moura, Mecking e Scarpin (2013) relacionaram a competitividade de mercado, como fator contingencial, com decisões sobre investimentos em ativos intangíveis e com eficiência na utilização dos ativos fixos. A análise foi realizada em companhias abertas listadas na BM\&FBOVESPA no período de 2008 a 2012. Os resultados demonstraram que as empresas que estavam em ambientes mais competitivos possuíam maiores proporções de ativos intangíveis e melhores combinações de investimentos e imobilizados relacionados com seus intangíveis.

Sobrinho et al. (2014) investigaram o impacto da competição do mercado, no componente do lucro contábil e no retorno das ações em uma amostra de companhias abertas listadas na BM\&FBOVESPA no período de 2006 e 2012. Os resultados, de modo geral, evidenciaram que o nível de competição alterava a relevância do fluxo de caixa em setores menos competitivos e os retornos eram superiores.

Moura e Klann (2016) analisaram a relação existente entre competitividade de mercado e utilização de hedge em companhias abertas, também sob a ótica da Teoria da Contingência. A amostra estudada foi composta por companhias abertas participantes do nível 1, nível 2 e novo mercado da BM\&FBovespa e a investigação foi realizado no ano de 2011. Verificaram que a competitividade influenciava para maior utilização de hedge.

Laksmana e Yang (2014) analisaram a associação entre competitividade de mercado e a prática de gerenciamento de resultados em uma amostra composta por companhias abertas americanas no período de 1998 a 2007. Os resultados demonstraram que a competitividade de mercado estava negativamente associada à prática do gerenciamento de resultados.

Liao e Lin (2016) analisaram como a competitividade de mercado influenciava na prática do gerenciamento de resultados de empresas americanas, em torno de anúncios de recompra de ações. O período investigado foi de 1990 a 2007. Constataram que empresas situadas em ambientes de maior competitividade e que realizavam recompra de ações praticavam significativamente menos gerenciamento de resultados.

É possível perceber, a partir dos resultados dos estudos apresentados, que a competitividade influenciou em diversos aspectos. Sendo assim, depreende-se que a competitividade pode provocar alterações no ambiente 
interno das empresas. Ou seja, o nível de competitividade pode se tornar um fator contingencial que afeta a estrutura interna das companhias. Por conseguinte, também pode ser um fator capaz de provocar impactos no comportamento dos gestores, no que se refere à prática do gerenciamento de resultados.

\subsection{Gerenciamento de resultados}

O gerenciamento de resultados, segundo Vladu e Cuzdriorean (2014), é um dos temas de maior interesse nas pesquisas contemporâneas, além de ser uma das discussões de maior significância nos últimos anos, principalmente na área de Contabilidade. Para Schipper (1989), o gerenciamento é uma intervenção proposital que ocorre no processo de relato financeiro externo, realizado com a intenção de obter algum ganho privado.

De acordo com Healy e Whalen (1999) o gerenciamento, muitas vezes, ocorre quando os gestores utilizam-se das demonstrações financeiras e da estruturação de transações para alterar as informações divulgadas, com a finalidade de ludibriar os stakehorders sobre o real desempenho econômico da empresa. De modo geral, o gerenciamento de resultados está relacionado com as várias maneiras que uma empresa possui para aumentar ou diminuir seu resultado, utilizando-se de procedimentos "legais" e previstos nas normas (LOPES; MARTINS, 2005).

É por meio do regime de competência que as receitas $e$ as despesas devem ser reconhecidas na contabilidade no momento em que ocorrem. Então, independente de serem recebidas ou pagas, é neste confronto de contas que se apura o lucro ou prejuízo contábil, e também é nesse momento que pode ocorrer o gerenciamento por meio dos accruals (LOPES; MARTINS, 2005).

Martinez (2008) descreve que a diferença entre o lucro líquido e o fluxo de caixa operacional líquido é denominada como accruals. O autor (2008, p. 8) menciona que "[...] accruals seriam todas aquelas contas de resultado que entraram no cômputo do lucro, mas que não implicam em necessária movimentação de disponibilidades". Também relata que nada de errado há no registro de accruals, mas que o problema existe quando o gestor discricionariamente procura aumentar ou diminuir os accruals com o objetivo de influenciar no resultado.

Considerando que os gestores podem influenciar nos accruals com a finalidade de obter benefícios próprios, há a necessidade de subdividi-los em: accruals discricionários e accruals não discricionários (HEALY, 1985; MARTINEZ, 2008). De acordo com Martinez (2008) os accruals não discricionários são aqueles oriundos da realidade do negócio, e os accruals discricionários são os artificiais, que tem como objetivo gerenciar o resultado contábil.

Portanto, para Martinez (2008, p. 8) "os accruals discricionários são uma proxy do gerenciamento de resultados contábeis". O autor também descreve que o grande desafio dos diversos trabalhos sobre o tema, "[...] é estimar o valor dos accruals discricionários (AD). Os $\mathrm{AD}$ podem ser positivos ou negativos, representando, respectivamente, que a empresa está gerenciando seus resultados para melhorá-los ou piorá-los". Além disso, o autor destaca a existência de modelos como o de HEALY (1985), Modelo de Jones (1991), Modelo modificado de Jones, elaborado por Dechow, Sloan e Sweeney (1995) e o Modelo de Kang-Sivaramakrishnan (1995) que procuram separar o componente discricionário do não-discricionário, no resultado contábil.

Outra questão importante, relacionada ao gerenciamento de resultados, de acordo com Almeida (2010), refere-se ao entendimento da diferença entre o gerenciamento e a fraude. Enquanto o primeiro interfere na contabilidade dentro do que a lei permite, a segunda extrapola os limites, procura distorcer valores e adulterar documentos. Os objetivos dos gestores, conforme Lo (2008), ao praticarem gerenciamento de resultados, pode ser resumido em aumentar o lucro por ação, sustentar desempenho, suavizar e apresentar resultados favoráveis.

\section{Procedimentos Metodológicos}

Para atender ao objetivo proposto, realizou-se pesquisa descritiva, conduzida por meio de análise documental e abordagem quantitativa. A população da pesquisa compreendeu as companhias abertas da B3 S. A. - Brasil, Bolsa, Balcão. As empresas que não tinham informações necessárias para as variáveis utilizadas foram excluídas da amostra. 
Após os procedimentos metodológicos adotados, a amostra da pesquisa foi composta por 277 companhias em 2010, 284 em 2011, 288 em 2012, 289 em 2013 e 284 em 2014. Portanto, a pesquisa foi realizada com dados de um período de 5 anos (2010 a 2014). Adotou-se como marco inicial o ano de 2010 porque este foi o período inicial de adoção plena das normas internacionais de contabilidade no Brasil.

A investigação se concentrou no período de 2010 a 2014, a fim de estabelecer um corte temporal capaz de contribuir para a literatura. Ressalta-se que o período de 5 anos está em consonância com Barros, Soares e Lima (2013) que analisaram o gerenciamento de resultados em uma amostra de companhias abertas no período de 2008 a 2010, ou seja, 3 anos. Também é similar ao estudo de Holz e Sarlo Neto (2014) que investigaram a relevância da informação contábil e a informatividade dos lucros em uma amostra de companhias abertas no período de 2008 a 2011, portanto, 4 anos. Também em consonância com Moura et al. (2016) que analisaram o gerenciamento em um conjunto de companhias abertas no período de 2010 a 2013, ou seja, um período de 4 anos.

Inicialmente foi calculado a competitividade de mercado, cuja proxy utilizada foi o índice de Herfindahl-Hirschman (HHI), que mensura a concentração de mercado por meio da soma dos quadrados das parcelas (market share) de cada empresa, o que possibilita caracterizar o tipo de concorrência em que tais empresas se encontram (LIJESEN, 2004).

Por exemplo, se em um determinado setor existirem duas empresas e cada uma possuir exatamente $50 \%$ das vendas, então, o HHI será $(0,5)^{2}+(0,5)^{2}$ $=0,5$. Se no setor existirem três companhias, uma com $50 \%$ e as outras com o restante ( $25 \%$ cada), então o HHI será $(0,5)^{2}+(0,25)^{2}+(0,25)^{2}=0,375$. Deste modo, quanto menor o índice, maior é a competitividade do setor (LIJESEN, 2004; BENSANKO et al., 2006).

A avaliação da competitividade por meio do índice $\mathrm{HHI}$ já foi realizada por outros pesquisadores, tais como Dhaliwal et al. (2008), Almeida (2010), Sobrinho et al. (2014), Moura e Klann (2016), Laksmana e Yang (2014) e Liao e Lin (2016) em que o índice é calculado pela seguinte equação:

$$
\mathrm{HHI}=\sum_{t=1}^{n} \beta i^{2}
$$

Em que $\beta i$ representa o percentual do ativo total da empresa em relação ao total da amostra. Ressalta-se que os valores de ativo total das companhias foram obtidos por meio do banco de dados Economática. Assim como nos estudos de Lijesen (2004), Dhaliwal et al. (2008), Almeida (2010), Sobrinho et al. (2014), Moura e Klann (2016), Laksmana e Yang (2014) e Liao e Lin (2016) optou-se por utilizar valores de ativo total ao invés do total de vendas, pois, conforme apontam esses autores, o ativo total tem menor oscilação no decorrer dos períodos e captura outras características, como tamanho e ativos controlados pelas companhias.

Em seguida, foi identificado o gerenciamento de resultados. Para isso, foi necessário determinar os accruals totais, pela comparação entre o lucro líquido e o fluxo de caixa operacional das empresas, calculado pelo método indireto. Após, por regressão matemática, foram estimados os accruals discricionários. Destaca-se que, também para o cálculo do gerenciamento de resultados, os dados foram obtidos no banco de dados Economática e para o cálculo da regressão linear, entre vários métodos, utilizou-se o modelo Jones Modificado (DECHOW; SLOAN; SWEENEY, 1995), conforme Equação 1:

$\mathrm{AT}_{\mathrm{i}, \mathrm{t}}==\alpha_{1}\left(\frac{1}{\mathrm{~A}_{\mathrm{i}, \mathrm{t}-1}}\right)+\alpha_{2}\left(\frac{\Delta \mathrm{RT}_{\mathrm{i}, \mathrm{t}}-\Delta \mathrm{CR}_{\mathrm{i}, \mathrm{t}}}{\mathrm{A}_{\mathrm{i}, \mathrm{t}-1}}\right)+\alpha_{3}\left(\frac{\Delta \mathrm{P}_{\mathrm{i}, \mathrm{t}}}{\mathrm{A}_{\mathrm{i}, \mathrm{t}-1}}\right)+\varepsilon_{\mathrm{i}, \mathrm{t}}$

Em que:

- $\mathrm{AT}_{\mathrm{i}, \mathrm{t}}=$ Accruals totais da empresa $i$ no ano $t$;

- $\mathrm{A}_{\mathrm{i}, \mathrm{t}-1}=$ Ativo total da empresa no final do ano $t-1$;

- $\Delta \mathrm{RT}_{\mathrm{i}, \mathrm{t}}=$ Variação da receita líquida da empresa $i$ do ano $t-1$ para o ano $t$;

- $\Delta \mathrm{CR}_{\mathrm{i}, \mathrm{t}}=$ Variação da conta duplicatas a receber (clientes) da empresa $i$ do ano $t-1$ para o ano $t$;

- $\mathrm{AP}_{\mathrm{i}, \mathrm{t}}=$ Ativo imobilizado e diferido da empresa $i$ no ano $t$;

- $\varepsilon_{\mathrm{i}, \mathrm{t}}=$ resíduo da regressão para a empresa $i$ no ano $t$.

No cálculo, ocorreu a ponderação das variáveis pelos ativos totais do início do período para evitar a influência do tamanho da empresa nos resultados. O modelo Jones Modificado é um dos mais utilizados na literatura por fornecer uma maior praticidade na execução. Como exemplo de estudos nacionais que utilizaram o modelo Jones Modificado podem ser citados Coelho e Lopes (2007), Nardi et al. (2009), Formigoni 
et al. (2012), Silva et al. (2014), Mazzioni et al. (2015) e Moura et al. (2016).
Por fim, foram coletados os dados das variáveis de controle, que também podem influenciar no gerenciamento de resultados, conforme Quadro 1:

Quadro 1 - Quadro das variáveis de controle da pesquisa

\begin{tabular}{|c|c|c|c|}
\hline VARIÁVEIS DE CONTROLE & $\begin{array}{c}\text { Descrição } \\
\text { Como calcular }\end{array}$ & FONTE DE DADOS & Autores \\
\hline $\begin{array}{l}\text { Proporções de } \\
\text { ativos intangíveis }\end{array}$ & $\begin{array}{l}\text { Total dos ativos intangíveis } \\
\text { Ativo total }\end{array}$ & Banco de dados Economática & $\begin{array}{l}\text { Moura, Theiss e Cunha (2014), } \\
\text { Moura, Ziliotto e Mazzioni (2016) }\end{array}$ \\
\hline Concentração de Propriedade & $\begin{array}{l}\text { Percentual total de ações } \\
\text { em posse do controlador } \\
\text { (ON + PN) }\end{array}$ & $\begin{array}{l}\text { Formulários de Referência: } \\
\text { Seção } 15.2 \text { - Posição acionária. }\end{array}$ & $\begin{array}{l}\text { Ball e Shivakumar (2005); Almeida } \\
\text { (2010); Hadani, Goranova e Khan } \\
\text { (2011) }\end{array}$ \\
\hline Governança Corporativa & $\begin{array}{l}\text { Variável dummy: } \\
\text { Listada no IGCX }=1 \\
\text { Não listada no IGCX }=0\end{array}$ & Website da BM\&FBovespa & $\begin{array}{l}\text { Chi et al. (2015); Mazzioni et al. } \\
\text { (2015); Xue e Hong (2016) }\end{array}$ \\
\hline Tamanho & Logaritmo do Ativo Total & Banco de dados Economática & $\begin{array}{l}\text { Dhaliwal et al. (2008); Almeida } \\
\text { (2010); Laksmana e Yang (2014) }\end{array}$ \\
\hline
\end{tabular}

Fonte: Elaborado pelos autores.

Conforme é possível verificar no Quadro 1, os dados foram coletados no banco de dados Economática, nos Formulários de Referência das empresas, no website da BM\&FBOVESPA e referem-se ao período de 2010 a 2014.

Após a coleta dos dados, realizou-se a análise. Inicialmente, ocorreu uma análise descritiva das principais variáveis de interesse da pesquisa. Em seguida, a análise de regressão linear múltipla foi realizada para verificar a influência da competitividade e das demais variáveis de controle no gerenciamento de resultados.

Destaca-se que foram observados os pressupostos de normalidade, por meio do teste de Kolmogorov-Smirnov; multicolinearidade, por meio do fator de inflação de variância - VIF e Tolerance; homocedasticidade, por meio do teste de Pesarán-Pesarán; e ausência de autocorrelação serial, por meio do teste de Durbin-Watson.

\section{Descrição e Análise dos Dados}

Esta seção contém a descrição e análise dos dados coletados. Primeiramente, apresentam-se os índices de competitividade por setor econômico no período de 2010 a 2014. Em seguida, as estatísticas descritivas da variável gerenciamento de resultados. Por fim, demonstram-se os resultados da regressão linear múltipla que possibilitou alcançar o objetivo do estudo.
Na Tabela 1, estão descritos os índices de Herfindahl, utilizados como proxy para competitividade, em seus valores originais. Quanto menor for o índice, maior será a competitividade do setor. Nesse sentido, Bensanko et al. (2006) apresentou três classificações para os resultados do índice de Herfindahl: concorrência perfeita, oligopólio e monopólio.

Bensanko et al. (2006) explica que quando os índices estão abaixo de 0,20 a concorrência tende a ser perfeita, ou seja, existe um grande número de produtores e consumidores e nenhuma empresa pode, por si só, influenciar o mercado. Então, a intensidade da concorrência pode ser feroz.

A segunda classe, denominada de oligopólio, surge quando os índices estão entre 0,20 e 0,60. Nesta classe, um grupo de empresas promove o domínio de determinada oferta de produtos ou serviços e, por isso, é necessário que cada uma considere o comportamento $e$ a reação das outras quando tomam decisões de mercado. Nesta classe, a concorrência pode ser feroz ou leve, dependendo da rivalidade entre as empresas.

A última classe, que Bensanko et al. (2006) denomina de monopólio, origina-se quando os índices são superiores a 0,60. Nesses casos há uma única empresa que detém o mercado de um determinado produto ou serviço, consegue impor seus preços e, assim, a intensidade da concorrência costuma ser leve, a não ser que seja ameaçada pela entrada de novas empresas. 
Tabela 1 - Estatística descritiva dos índices de competitividade do período de 2010 a 2014

\begin{tabular}{|c|c|c|c|c|c|}
\hline $\begin{array}{c}\text { SETOR ECONÔMICO } \\
\text { DA BM\&FBOVESPA }\end{array}$ & $\begin{array}{l}\text { HHI } \\
2010\end{array}$ & $\begin{array}{l}\text { HHI } \\
2011\end{array}$ & $\begin{array}{l}\text { HHI } \\
2012\end{array}$ & $\begin{array}{l}\text { HHI } \\
2013\end{array}$ & $\begin{array}{c}\text { HHI } \\
2014\end{array}$ \\
\hline Bens industriais & 0,12 & 0,12 & 0,12 & 0,14 & 0,16 \\
\hline Construção e transporte & 0,05 & 0,05 & 0,05 & 0,04 & 0,04 \\
\hline Consumo cíclico & 0,05 & 0,05 & 0,05 & 0,05 & 0,06 \\
\hline Consumo não cíclico & 0,11 & 0,10 & 0,09 & 0,10 & 0,11 \\
\hline Financeiro e outros & 0,18 & 0,18 & 0,18 & 0,20 & 0,20 \\
\hline Materiais básicos & 0,17 & 0,18 & 0,18 & 0,19 & 0,19 \\
\hline $\begin{array}{l}\text { Petróleo, gás e biocombus- } \\
\text { tíveis }\end{array}$ & 0,92 & 0,90 & 0,89 & 0,92 & 0,94 \\
\hline Tecnologia da informação & 0,60 & 0,40 & 0,39 & 0,37 & 0,37 \\
\hline Telecomunicações & 0,20 & 0,27 & 0,28 & 0,34 & 0,36 \\
\hline Utilidade pública & 0,12 & 0,12 & 0,12 & 0,10 & 0,09 \\
\hline
\end{tabular}

Fonte: Elaborada pelos autores.

Nota-se na Tabela 1, que existe uma predominância de setores que apresentaram concorrência perfeita, ou seja, com índices abaixo de 0,20. Nota-se que em sete (bens industriais, construção e transporte, consumo cíclico, não cíclico, financeiro, materiais básicos e utilidade pública) dos dez setores os índices não ultrapassaram 0,20, indicando uma alta competitividade.

Também é possível verificar que, nestes sete setores, além do setor de bens industriais que se elevou de 0,12 em 2010 para 0,16 em 2014, indicando redução de competitividade e do setor de utilidade pública que apresentou redução de 0,12 em 2010 para 0,09 em 2014, apontando aumento do nível de competitividade, os demais setores, praticamente, se mantiveram estáveis ao longo do período.

É possível observar que o setor econômico de petróleo, gás e biocombustíveis se destacou com os maiores índices ao longo de todo o período de 2010 a 2014. Nesse setor, de acordo com a classificação de Bensanko et al. (2006), ocorre um monopólio em virtude da alta participação no mercado, exercida por uma empresa. Destaca-se que este foi o único setor econômico que atingiu um índice superior a 0,60 que caracteriza o ambiente de monopólio.

No setor de petróleo, gás e biocombustíveis, ao longo do período estudado, haviam 8 empresas que disputavam o mercado, sendo que uma apresentou um ativo total médio no período que equivalia a $97 \%$ do setor, indicando que as outras sete empresas juntas representam apenas 3\%. Além disso, é possível perceber que o indicador se elevou de 0,92 em 2010 para 0,94 em 2014, ou seja, ocorreu um pequeno aumento do monopólio.

É possível perceber, ainda na Tabela 1 , que 2 setores apresentam índices entre 0,20 e 0,60 que, de acordo com Bensanko et al. (2006), resultam em oligopólios. Trata-se do setor de Tecnologia da Informação e do setor de Telecomunicações. Todavia, ocorre uma situação inversa entre ambos. Enquanto no setor de Tecnologia da informação o nível de competitividade aumentou consideravelmente, no setor de telecomunicações houve uma significativa redução de competitividade.

Nota-se na Tabela 1 que o índice no setor de tecnologia da informação reduziu de 0,60, limite para a barreira do monopólio, em 2010, para 0,37 em 2014. Neste setor, duas empresas distanciam-se das demais empresas do setor. Todavia, tal redução no índice deu-se em razão da diminuição da participação no mercado por parte de ambas, principalmente em função da entrada de mais empresas no setor ao longo do período. Destaca-se uma possível tendência no setor, de se dirigir a caminho da concorrência perfeita.

Contrariamente, no setor econômico de Telecomunicações, o índice elevou-se de 0,20 em 2010, para 0,36 em 2014. No ano de 2010, 5 empresas destacavam-se no setor, sendo que estas 5 empresas 
apresentavam uma participação de mercado superior a $90 \%$. Porém, principalmente em razão da diminuição da participação de duas delas, o domínio do setor passou a ser realizado por apenas três. Dentre as três empresas que dominavam o mercado no ano de 2014, uma delas dá indícios de que não acompanhará o crescimento das outras duas, no decorrer dos anos. Sendo assim, o cenário de oligopólio, ou seja, concorrência imperfeita tende a se fortalecer.

De modo geral, os resultados foram similares aos evidenciados por Moura, Mecking e Scarpin (2013) que analisaram uma amostra composta por $268 \mathrm{com}$ panhias abertas no período de 2008 a 2010 e também identificaram índices que caracterizam um cenário de concorrência perfeita nos setores de bens industriais, construção e transporte, consumo cíclico e não cíclico, materiais básicos e no de utilidade pública. Assim como identificaram um monopólio no setor de petróleo, gás e biocombustíveis. No entanto, os resultados divergiram em relação ao setor financeiro, de tecnologia da informação e de telecomunicações. Mas, é importante destacar que a diferença de resultados pode ser decorrente dos critérios de formação da amostra.

Na Tabela 2, apresentam-se os índices de gerenciamento de resultados das empresas da amostra, referentes ao período de 2010 a 2014.

Por meio da Tabela 2, verifica-se que no ano de 2010, de modo geral, o número de empresas que realizaram gerenciamentos para redução e para aumento dos resultados foram semelhantes, ou seja, $50 \%$ $(21+29)$ e $50 \%(31+19)$, respectivamente. Todavia, destaca-se que em $60 \%(29+31)$ das empresas os ajustamentos de competência ocorreram em menores proporções $(-0,10$ e 0,10$)$ e, na maioria dos casos, visando aumentar os resultados contábeis.

Quanto ao ano de 2011, constata-se na Tabela 2 que o percentual de empresas que realizaram gerenciamentos negativos de baixas proporções $(-0,10$ a 0$)$ elevou-se consideravelmente, passando de $29 \%$ em 2010 para $44 \%$ em 2011. O percentual de empresas que realizaram gerenciamentos negativos de maiores proporções teve uma pequena redução de $21 \%$ para $18 \%$ em 2011. Destaca-se ainda, no ano de 2011, que o percentual de empresas que realizaram gerenciamento positivo de maior proporção reduziu para apenas $7 \%$ do total de 284 que compuseram a amostra.
Tabela 2 - Estatística descritiva dos índices de gerenciamento de resultados do período de 2010 a 2014

\begin{tabular}{|c|c|c|c|}
\hline \multirow{2}{*}{ ○ } & \multirow{2}{*}{$\begin{array}{c}\text { INDICADORES DE } \\
\text { GERENCIAMENTO DE RESULTADOS } \\
\text { (ACCRUALS DISCRICIONÁRIOS) }\end{array}$} & \multicolumn{2}{|c|}{$\begin{array}{l}\text { QUANTIDADE } \\
\text { DE EMPRESAS }\end{array}$} \\
\hline & & $\mathbf{N}^{\circ}$ & $\%$ \\
\hline \multirow{4}{*}{$\begin{array}{l}\circ \\
\stackrel{\circ}{\circ} \\
\stackrel{\sim}{N}\end{array}$} & $<-0,10$ & 57 & 21 \\
\hline & $-0,10$ a 0,00 & 80 & 29 \\
\hline & 0,01 a 0,10 & 87 & 31 \\
\hline & $>0,10$ & 53 & 19 \\
\hline \multirow{4}{*}{ ت্) } & $<-0,10$ & 52 & 18 \\
\hline & $-0,10$ a 0,00 & 125 & 44 \\
\hline & 0,01 a 0,10 & 86 & 30 \\
\hline & $>0,10$ & 21 & 7 \\
\hline \multirow{4}{*}{ 궁 } & $<-0,10$ & 35 & 12 \\
\hline & $-0,10$ a 0,00 & 113 & 39 \\
\hline & 0,01 a 0,10 & 107 & 37 \\
\hline & $>0,10$ & 33 & 11 \\
\hline \multirow{4}{*}{$\stackrel{m}{\circ}$} & $<-0,10$ & 31 & 11 \\
\hline & $-0,10$ a 0,00 & 114 & 39 \\
\hline & 0,01 a 0,10 & 111 & 38 \\
\hline & $>0,10$ & 33 & 11 \\
\hline \multirow{4}{*}{ 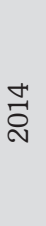 } & $<-0,10$ & 30 & 10 \\
\hline & $-0,10$ a 0,00 & 100 & 35 \\
\hline & 0,01 a 0,10 & 129 & 45 \\
\hline & $>0,10$ & 28 & 10 \\
\hline
\end{tabular}

Fonte: Elaborada pelos autores.

Em relação ao ano de 2012 é possível verificar na Tabela 2 que o percentual de empresas que realizaram gerenciamentos negativos de baixas proporções $(-0,10$ a 0) reduziu de $44 \%$ em 2011 para 39\% em 2012. Nota-se que também reduziu, de 2011 para 2012, o percentual de empresas que realizaram gerenciamentos negativos de maiores proporções. Verifica-se ainda na Tabela 2 que, em 2012, o percentual de empresas que realizaram gerenciamentos positivos de menores e maiores proporções aumentou de $38 \%(30 \%+7 \%)$ em 2011 para 49\% (37\% + 11\%) em 2012.

No tocante a 2013, observa-se na Tabela 2 que não ocorreram alterações representativas no comparativo com o ano de 2012. Entretanto, no que se refere ao ano de 2014, é possível constatar uma pequena 
redução nos percentuais de empresas que realizaram gerenciamentos negativos de menores e maiores proporções de 2013 para 2014, bem como no percentual de empresas que realizaram gerenciamentos positivos de maiores proporções. Ainda analisando a Tabela 2 , verifica-se um aumento significativo no percentual de empresas que realizaram gerenciamentos positivos de pequenas proporções $(0,01-0,10)$, pois, o percentual elevou-se de 38\% em 2013 para 45\% 2014.

De modo geral, os resultados foram similares aos evidenciados por Mazzioni et al. (2015) e por Moura et al. (2016) que investigaram o gerenciamento de resultados em amostras de empresas no período de 2010 a 2013 e que também identificaram índices de gerenciamentos de baixas proporções na maioria dos casos.

Na Tabela 3, apresenta-se uma síntese do modelo da equação da regressão linear múltipla, que possibilita analisar o poder preditivo da competitividade em relação ao gerenciamento de resultados das empresas da amostra.

Tabela 3 - Modelo da equação da influência da competitividade no gerenciamento de resultados do período de 2010 a 2014

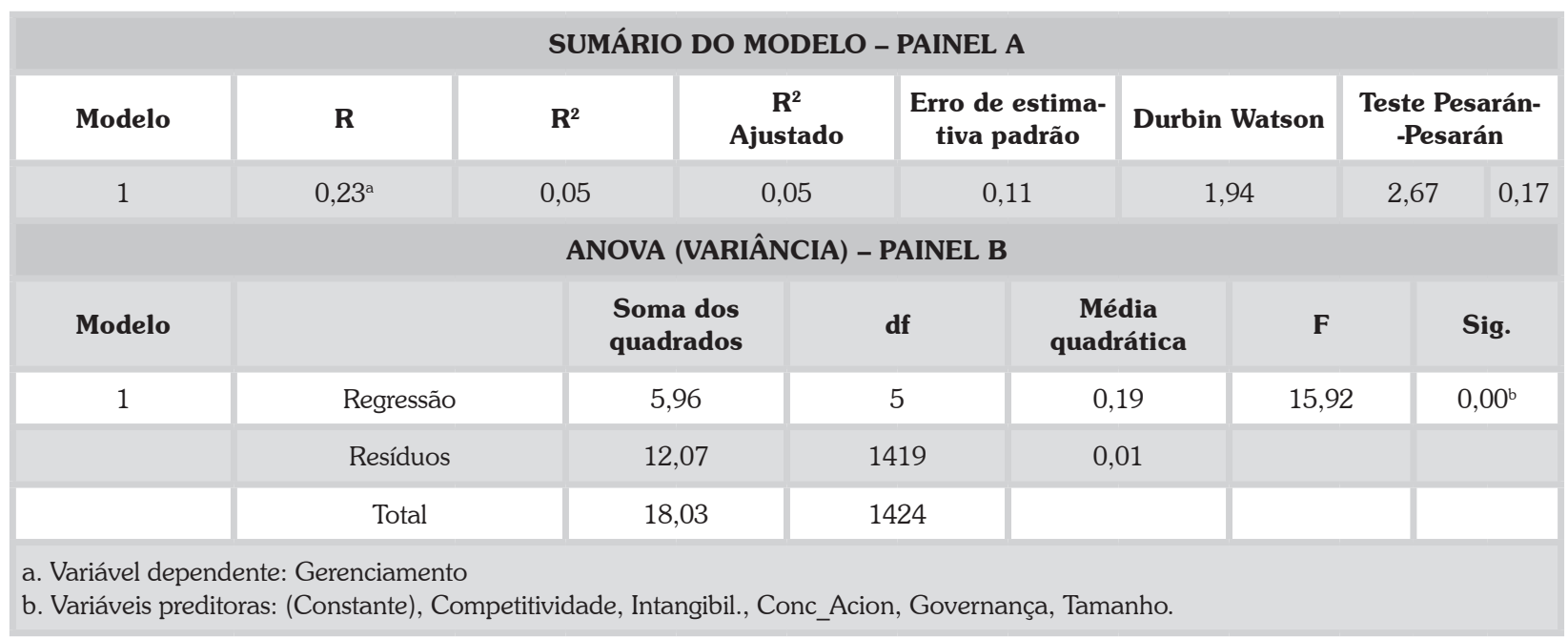

Fonte: Elaborada pelos autores.

Observa-se no Painel A da Tabela 3 que o grau de associação entre a variável dependente e as variáveis independentes apresenta coeficiente de correlação $R$ de $23 \%$. Quanto ao coeficiente de determinação ou poder explicativo da regressão $\mathrm{R}^{2}$, registrou-se um valor de $5 \%$. Nota-se ainda no Painel A que o $\mathrm{R}^{2}$ ajustado também foi equivalente a $5 \%$.

O resultado da estatística de Durbin-Watson demonstra que não há problemas de autocorrelação dos resíduos, já que o seu valor foi de 1,94 e o teste do comportamento dos resíduos (Pesarán-Pesarán) demonstra que o pressuposto da homocedasticidade não foi violado.

No Painel B da Tabela 3, verifica-se ainda que o modelo de regressão linear múltipla estimado acrescentou um poder explicativo de $5,96 \%$ e que o teste F-ANOVA foi significante $(0,00)$. Ou seja, o conjunto de variáveis independentes exerce influência sobre a variável dependente.

$\mathrm{Na}$ Tabela 4, apresentam-se os coeficientes da regressão, que possibilitam analisar o poder preditivo da competitividade sobre o gerenciamento de resultados (dependente). Contudo, ressalta-se que os indicadores de gerenciamento podem ser tanto positivos, quanto negativos. Logo, apesar do indicador em uma determinada empresa ser negativo, $-0,10$, por exemplo, não significa que, proporcionalmente, o gerenciamento foi menor do que o praticado em uma empresa que apresentou indicador positivo equivalente a 0,10 . A diferença é que, enquanto uma delas realizou gerenciamento para reduzir o resultado, a outra, realizou para aumentar o resultado.

Entretanto, em termos proporcionais, o gerenciamento realizado foi similar. Por isso, neste estudo, ao 
gerar a regressão, foram utilizados os indicadores de gerenciamento em valores absolutos, haja vista que, quanto mais distante de zero for o índice, seja positivo ou negativo, significa que haverá maior gerenciamento nos resultados. Deste modo, para não gerar uma regressão equivocada foram ignorados os sinais negativos $e$ foram considerados os índices em valores absolutos.

Tabela 4 - Coeficientes da equação da influência da competitividade no gerenciamento de resultados do período de 2010 a 2014

\begin{tabular}{|c|c|c|c|c|c|c|c|}
\hline \multicolumn{8}{|c|}{ COEFICIENTES } \\
\hline \multirow{2}{*}{ VARIÁVEIS } & \multicolumn{2}{|c|}{ Não PADRONIZADOS } & \multirow{2}{*}{$\begin{array}{c}\text { Padroniz. } \\
\text { Beta }\end{array}$} & \multirow{2}{*}{$\mathbf{T}$} & \multirow{2}{*}{ Sig. } & \multicolumn{2}{|c|}{$\begin{array}{l}\text { EsTATíSTICA DE } \\
\text { COLINEARIDADE }\end{array}$} \\
\hline & B & $\begin{array}{c}\text { ERRO } \\
\text { PADRÃo }\end{array}$ & & & & Tolerance & VIF \\
\hline (Constante) & 0,29 & 0,02 & & 12,03 & 0,00 & & \\
\hline Competitividade & 0,03 & 0,05 & 0,02 & 0,65 & 0,52 & 0,91 & 1,09 \\
\hline Intangibil & $-0,03$ & 0,02 & $-0,05$ & $-1,76$ & 0,08 & 0,97 & 1,03 \\
\hline Conc_Acion & $-0,00$ & 0,00 & $-0,03$ & $-0,97$ & 0,33 & 0,93 & 1,08 \\
\hline Governança & $-0,01$ & 0,01 & $-0,05$ & $-1,69$ & 0,09 & 0,76 & 1,31 \\
\hline Tamanho & $-0,03$ & 0,00 & $-0,23$ & $-7,78$ & 0,00 & 0,73 & 1,36 \\
\hline
\end{tabular}

Fonte: Elaborada pelos autores.

Nota-se na Tabela 4 que o fator de inflação de variância (VIF) e o Tolerance (fator diretamente relacionado com o valor de tolerância) apresentaram valores próximo a 1. Então, nesse caso não há problema de multicolinearidade entre as variáveis independentes do modelo, pois, de acordo com Hair Jr. et al. (2005), um VIF é considerado alto quando está acima de dez.

Em relação à principal variável de análise, competitividade, é possível verificar na Tabela 4 que o coeficiente positivo de 0,03 revela indícios de que maior competitividade influência para redução nas práticas de gerenciamento. No caso da variável competitividade, quanto maior é o índice $\mathrm{HHI}$, menor é a competitividade entre as empresas, por isso, a relação positiva identificada na regressão revela o contrário (menor gerenciamento). Porém, destaca-se que a falta de significância estatística para a variável competitividade não permite afirmar que o resultado é confiável.

Dentre as variáveis classificadas como de controle, apresentaram-se estatisticamente significantes e com coeficientes negativos, respectivamente, intangibilidade (Coef. - $0,03 / \mathrm{Sig}=0,08$ ), governança corporativa
(Coef. $=-0,01 /$ Sig. $=0,09)$ e tamanho (Coef. $=-0,03$ / Sig. $=0,00$ ). Estes resultados indicam que maior nível de intangibilidade, melhores práticas de governança e quanto maior for a empresa menores serão as possibilidades de gerenciamento de resultados. Já a variável concentração acionária, apesar de também indicar uma influência negativa no gerenciamento, mostrou-se não significante estatisticamente (Coef. = $-0,00 /$ Sig. $=0,33$ ).

Os resultados estão alinhados aos de Almeida (2010) que investigou a influência do ambiente competitivo na qualidade das demonstrações contábeis em uma amostra composta por companhias abertas no período de 1996 a 2006 e que constatou que companhias em ambientes com alta competição não reduziam as práticas de gerenciamento de resultados. Também foi similar aos de Kordestani e Mohammadi (2016) que analisaram uma amostra composta por companhias abertas listadas na bolsa de valores do Teerã, no Irã, no período de 2002 a 2011 e não encontraram relação entre competitividade de mercado e o gerenciamento de resultados. 
Sendo assim, na amostra analisada, os resultados sinalizam que a competitividade não pode ser considerada um fator contingencial que influencia na prática do gerenciamento de resultados, pois, de acordo com os resultados expostos na Tabela 4, não se pode afirmar estatisticamente que a competitividade influencia menores práticas de gerenciamento de resultados.

\section{Considerações Finais}

O estudo teve como objetivo verificar a influência da competitividade de mercado no gerenciamento de resultados das companhias abertas listadas na BM\&FBOVESPA, sob a ótica da Teoria da Contingência. Para atingir esse objetivo realizou-se uma pesquisa descritiva, conduzida por meio de análise documental e abordagem quantitativa dos dados, que se referem ao período de 2010 a 2014. E, a amostra da pesquisa foi composta por 277 companhias em 2010, 284 em 2011, 288 em 2012, 289 em 2013 e 287 em 2014.

Em relação à competitividade de mercado, os resultados revelaram que no setor econômico de petróleo, gás e biocombustíveis há ocorrência de um monopólio em virtude da alta participação exercida por uma das empresas. Destacaram-se também os setores de tecnologia da informação e o de telecomunicações, em que os índices indicaram a existência de oligopólios. Nos demais setores (bens industriais, construção e transporte, consumo cíclico e não cíclico, financeiro, materiais básicos e utilidade pública) os índices apontaram para uma estrutura de concorrência perfeita. De modo geral, os resultados foram similares aos de Moura, Mecking e Scarpin (2013) que analisaram uma amostra composta por 268 companhias abertas no período de 2008 a 2010.

No que tange ao gerenciamento de resultados, os resultados se assemelham aos de Mazzioni et al. (2015) e Moura et al. (2016) que investigaram o gerenciamento de resultados em amostras de empresas no período de 2010 a 2013 e que também identificaram índices de gerenciamentos de baixas proporções na maioria dos casos.

Nesta pesquisa, no ano de 2010, a maioria das empresas realizaram gerenciamento de resultados em menores proporções e, na maioria dos casos, visando aumentar os resultados contábeis. Quanto ao ano de 2011, o percentual de empresas que realizaram gerenciamentos negativos de baixas proporções elevou-se consideravelmente, ao passo que o percentual de empresas que realizaram gerenciamentos positivos de baixa proporção manteve-se semelhante ao ano de 2010. Em 2012, ocorreu o contrário, o percentual de empresas que realizaram gerenciamentos negativos de baixas proporções reduziu e o percentual de empresas que realizaram gerenciamentos positivos de menores proporções elevou-se. No ano de 2013 não ocorreram alterações representativas no comparativo com o ano de 2012. Entretanto, no ano de 2014, ocorreu nova redução nos percentuais de empresas que realizaram gerenciamentos negativos de menores e maiores proporções.

Por fim, quanto à influência da competitividade de mercado no gerenciamento de resultados, o coeficiente da regressão linear múltipla revelou indícios de que maior competitividade influência para redução nas práticas de gerenciamento. Porém, a falta de significância estatística para a variável competitividade não permitiu afirmar que o resultado era confiável. $\mathrm{O}$ resultado encontrado se assemelha aos de Almeida (2010) e de Kordestani e Mohammadi (2016) que também constataram que companhias em ambientes com alta competição não reduziam as práticas de gerenciamento de resultados.

Desse modo, na amostra analisada neste estudo, para o período de 2010 a 2014, os resultados sinalizaram que a competitividade não pode ser considerada um fator contingencial que influencia na prática do gerenciamento de resultados. A partir de tais resultados, surgem inquietações as quais se sugere que sejam temas de investigação para futuras pesquisas. Assim, recomenda-se acompanhar os indicadores de competitividade e de gerenciamento de resultados. Também seria interessante investigar outros fatores diferentes do investigado neste estudo, a fim de verificar outras influências nas práticas de gerenciamento de resultados. Além disso, sugere-se também que se amplie a pesquisa utilizando outras métricas de avaliação do gerenciamento de resultados. 


\section{REFERÊNCIAS}

ALMEIDA, J. E. F. Qualidade da informação contábil em ambientes competitivos. 2010. Tese de Doutorado. Universidade de São Paulo, 2010.

AN, Z; LI, D.; YU, J. Earnings management, capital structure, and the role of institutional environments. Journal of Banking \& Finance, v. 68, p. 131-152, 2016.

BALL, R; SHIVAKUMAR, L. Earnings quality in UK private firms: comparative loss recognition timeliness. Journal of accounting and economics, v. 39, n. 1, p. 83-128, 2005.

BALL, R.; ROBIN, A.; WU, J. S. Incentives versus standards: properties of accounting income in four East Asian countries. Journal of accounting and economics, v. 36, n. 1, p. 235-270, 2003.

BAO, S. R.; LEWELLYN, K. B. Ownership structure and earnings management in emerging markets - An institutionalized agency perspective. International Business Review, 2017.

BARROS, M. E.; MENEZES, J. T.; COLAUTO, R. D.; TEODORO, J. D. Gerenciamento de Resultados e Alavancagem financeira em Empresas Brasileiras de Capital Aberto. Contabilidade, Gestão e Governança, v. 17, n. 1, 2014.

BARROS, C. M. E.; SOARES, R. O.; LIMA, G. A. S. F. A relação entre governança corporativa e gerenciamento de resultados em empresas brasileiras. Revista de Contabilidade e Organizações, v. 7, n. 19, 2013.

BESANKO, D.; DRANOVE, D.; SHANLEY, M.; SCHAEFER, S. A economia da estratégia. 3. ed. Porto Alegre: Bookman, 2006.

BURNS, J.; SCAPENS, R. W. Conceptualizing management accounting change: an institutional framework. Management accounting research, v. 11, n. 1, p. $3-25,2000$.

BURNS, T.; STALKER, G. M. The management of innovation. London: Tavistock, 1961.

BATEMAN, T.S; SNELL, S.A.; Administração: construindo vantagens competitiva. São Paulo: Atlas, 1998.
CARDOSO, R. L.; SOUZA, F. S. R. N.; DANTAS, M. Impactos da adoção do IFRS na acumulação discricionária e na pesquisa em gerenciamento de resultados no Brasil. Revista Universo Contábil, v. 11, n. 2, p. 65-84, 2015.

CHANDLER, A. D. Strategy and Structure: chapter in the history of the industrial enterprise. Massachusetts: The M.I.T. Press, 1962.

CHAKRABARTY, S. The influence of national culture and institutional voids on family ownership of large firms: A country level empirical study. Journal of International Management, v. 15, n. 1, p. 32-45, 2009.

CHI, C. W.; HUNG, K.; CHENG, H. W.; LIEU, P. T. Family firms and earnings management in Taiwan: Influence of corporate governance. International Review of Economics \& Finance, v. 36, p. 88-98, 2015.

COELHO, A. C. D.; LOPES, A. B. Avaliação da prática de gerenciamento de resultados na apuração de lucro por companhias abertas brasileiras conforme seu grau de alavancagem financeira. Revista de Administração Contemporânea, v. 11, n. SPE2, p. 121-144, 2007.

CRABTREE, A. MAHER, J. J.; WAN, Huishan. New debt issues and earnings management. Advances in Accounting, v. 30, n. 1, p. 116-127, 2014.

CUNHA, P. R.; HILLESHEIM, T.; FAVERI, D. B.; JUNIOR, M. M. R. Características do comitê de auditoria e o gerenciamento de resultados: um estudo nas empresas listadas na BM\&FBovespa. Revista de Contabilidade e Organizações, v. 8, n. 22, 2014.

DAI, Y.; KONG, D.; WANG, L. Information asymmetry, mutual funds and earnings management: Evidence from China. China Journal of Accounting Research, v. 6, n. 3, p. 187-209, 2013.

DHALIWAL, D. S.; RADHAKRISHNAN, S.; TSANG, A.; YANG, Y. G. Nonfinancial disclosure and analyst forecast accuracy: International evidence on corporate social responsibility disclosure. The Accounting Review, v. 87, n. 3, p. 723-759, 2012

DEBOSKEY, D. G.; JIANG, W. Earnings management and auditor specialization in the post-sox era: An examination of the banking industry. Journal of Banking \& Finance, v. 36, n. 2, p. 613-623, 2012. 
DECHOW, P. M.; SLOAN, R. G.; SWEENEY, A. P.

Detecting earnings management. Accounting review, $\mathrm{p}$. 193-225, 1995.

DONALDSON, L. Teoria da Contingência estrutural. In: CLEGG, S.R. et al. Handbook de estudos organizacionais: modelos e novas questões em estudos organizacionais. São Paulo: Atlas, 1999.

DYCK, A.; ZINGALES, L. Private benefits of control: An international comparison. The Journal of Finance, v. 59, n. 2, p. 537-600, 2004.

DHALIWAL, D.; HUANG, S.; KHURANA, I. K.;

PEREIRA, R. Product Market competition and accounting conservatism. Working papers series,v.13. USA, 2008.

ERFURTH, A; BEZERRA, F. Gerenciamento de resultados nos diferentes níveis de governança corporativa. Revista

Base (Administração e Contabilidade) da UNISINOS, v. 10, n. 1, 2013.

FEITO-RUIZ, I.; MENÉNDEZ-REQUEJO, Susana. Family firm mergers and acquisitions in different legal environments. Family Business Review, v. 23, n. 1, p. 60-75, 2010.

FORMIGONI, H.; ANTUNES, M. T. P.; PAULO, E.; PEREIRA, C. A. Estudo sobre os incentivos tributários para o gerenciamento de resultados contábeis nas companhias abertas brasileiras. Revista Base, v. 9, n. 1, p. 41-52, 2012.

FUNG, S. YK; GOODWIN, J. Short-term debt maturity, monitoring and accruals-based earnings management. Journal of Contemporary Accounting \& Economics, v. 9, n. 1, p. 67-82, 2013.

GHOUMA, H. How does managerial opportunism affect the cost of debt financing?. Research in International Business and Finance, v. 39, p. 13-29, 2017.

GRECCO, M. C. P. O Efeito da convergência brasileira às IFRS no gerenciamento de resultados das empresas abertas brasileiras não financeiras. BBR-Brazilian Business

Review, v. 10, n. 4, p. 117-140, 2013.

GUERRA, A. R. Arranjos entre fatores situacionais e sistema de contabilidade gerencial sob a ótica da teoria da contingência. 2007. Dissertação. (Mestrado em Controladoria e Contabilidade: Contabilidade) Faculdade de Economia, Administração e Contabilidade, Universidade de São Paulo, São Paulo, 2007.
HADANI, M.; GORANOVA, M.; KHAN, R. Institutional investors, shareholder activism, and earnings management. Journal of Business Research, v. 64, n. 12, p. 1352-1360, 2011.

HAIR, JR,; ANDERSON, R.E; TATHAM, R.L; BLACK, W.C. Análise multivariada de dados. 5 ed. Porto Alegre: Boockman, 2005.

HEALY, P. M. The effect of bonus schemes on accounting decisions. Journal of accounting and economics, v. 7, n. 1-3, p. 85-107, 1985.

HEALY, P. M.; WAHLEN, J. M. A review of the earnings management literature and its implications for standard setting. Accounting horizons, v. 13, n. 4, p. 365-383, 1999.

HOLTZ, L.; SARLO NETO, A. Efeitos das Características do Conselho de Administração sobre a Qualidade da Informação Contábil no Brasil. Revista Contabilidade \& Finanças-USP, v. 25, n. 66, 2014.

JUNQUEIRA, E. R. Perfil do sistema de controle gerencial sob a perspectiva da teoria da contingência. 2010. Tese (Doutorado) - Programa de Pós Graduação em Ciências Contábeis, Departamentos de Contabilidade e Atuária, Faculdade de Economia ,Administração e Contabilidade da Universidade de São Paulo, 2010.

KARUNA, C. Industry Product Market Competition and Corporate Governance. SSRN Working Paper. June, 2008

KANG, S-H.; SIVARAMAKRISHNAN, K. Issues in testing earnings management and an instrumental variable approach. Journal of accounting Research, p. 353367, 1995.

KAZEMIAN, S.; SANUSI, Z. M. Earnings management and ownership Structure. Procedia Economics and Finance, v. 31, p. 618-624, 2015.

KIM, I.; MILLER, S.; WAN, H.; WANG, B. Drivers behind the monitoring effectiveness of global institutional investors: Evidence from earnings management. Journal of Corporate Finance, v. 40, p. 24-46, 2016.

KIM, J-B.; SOHN, B. C. Real earnings management and cost of capital. Journal of Accounting and Public Policy, v. 32, n. 6, p. 518-543, 2013. 
KORDESTANI, G. R.; MOHAMMADI, M. R. A Study of the Relationship between Product Market Competition and Earnings Management. Procedia Economics and Finance, v. 36, p. 266-273, 2016.

LACOMBE, F.; HEILBORN, G. Administração Princípios e Tendências. São Paulo: Saraiva, 2003.

LAKSMANA, I; YANG, Y. Product market competition and earnings management: Evidence from discretionary accruals and real activity manipulation. Advances in

Accounting, v. 30, n. 2, p. 263-275, 2014.

LIAO, T-L.; LIN, W-C. Product market competition and earnings management around open-market repurchase announcements. International Review of Economics \& Finance, v. 44, p. 187-203, 2016.

LIJESEN, M. G. Adjusting the Herfindahl index for close substitutes: an application to pricing in civil aviation. Transportation Research Part E: Logistics and Transportation Review, v. 40, n. 2, p. 123-134, 2004.

LO, Kin. Earnings management and earnings quality. Journal of Accounting and Economics, v. 45, n. 2, p. 350-357, 2008.

LO, H-C.; WU, R-S.; KWEH, Q. Do institutional investors reinforce or reduce agency problems?

Earnings management and the post-IPO performance. International Review of Financial Analysis, v. 52, p. 62-76, 2017.

LO, K.; RAMOS, F.; ROGO, R. Earnings management and annual report readability. Journal of Accounting and Economics, v. 63, n. 1, p. 1-25, 2017.

LOPES, A. B.; MARTINS, E. Teoria da Contabilidade Uma nova abordagem. São Paulo: Atlas, 2005.

MARTINEZ, A. L. Detectando Earnings Management no Brasil: estimando accruals discricionários. Revista Contabilidade e Finanças, v. 19, n. 46, p. 7-17, 2008. MARTINEZ, A. L. Do corporate governance special listing segments and auditing curb real and accrual-based earnings management? Evidence from Brazil. Revista Universo Contábil, v. 7, n. 4, p. 98, 2011.
MAZZIONI, S.; PRIGOL, V.; MOURA, G. D.; KLANN, R. C. Influência da governança corporativa e da estrutura de capital no gerenciamento de resultados. Revista Contemporânea de Contabilidade, v. 12, n. 27, 2015.

MORCK, R. K.; STANGELAND, D. A.; YEUNG, B. Inherited wealth, corporate control and economic growth: the Canadian disease? In: Morck, Randall K., Concentrated Corporate Ownership, p. 319-369. Chicago: University of Chicago Press, 2000.

MOURA, G. D.; KLANN, R. C. Competitividade de mercado, hedge e hedge accounting: um estudo sob a ótica contingencial. Revista de Contabilidade da UFBA, v. 10, n. 3, p. 63-87, 2016.

MOURA, G. D.; MECKING, D. V.; SCARPIN, J. E. Competitividade de mercado, ativos intangíveis e eficiência na combinação dos ativos fixos em companhias abertas listadas na BM\&Fbovespa. Enfoque: Reflexão Contábil, v. 32, n. 3, p. 19-35, 2013.

MOURA, G. D.; MACÊDO, F. F. R. R.; MAZZIONI, S.; KRUGER, S. D. Análise da relação entre gerenciamento de resultados e custo de capital em empresas brasileiras listadas na bm\&fbovespa. Revista Catarinense da Ciência Contábil, v. 15, n. 44, 2016.

MOURA, G. D.; ZILIOTTO, K.; MAZZIONI, S. Fatores determinantes da qualidade da informação contábil em companhias abertas listadas na BM\&FBovespa. Revista de Contabilidade e Organizações, v. 10, n. 27, 2016.

NARDI, P. C. C.; SILVA, R. L. M.; NAKAO, S. H.; VALLE, M. R. A relação entre gerenciamento de resultados contábeis e o custo de capital das companhias abertas brasileiras. Revista Universo Contábil, v. 5, n. 4, p. 0626, 2009.

PAULO, E. Manipulação das Informações contábeis: uma análise teórica e empírica sobre os modelos operacionais de detecção de gerenciamento de resultados. 2007. (Doutorado em Ciências Contábeis) Programa de Pós Graduação em Ciências Contábeis, Departamento de Contabilidade e Atuária, Faculdade de Economia, Administração e Contabilidade da Universidade de São Paulo, 2007. 
PERSAKIS, A.; IATRIDIS, G. E. Audit quality, investor protection and earnings management during the financial crisis of 2008: An international perspective. Journal of International Financial Markets, Institutions and Money, v. 41, p. 73-101, 2016.

PICCOLI, P. G. R.; SOUZA, A.; SILVA, W. V. As práticas de governança corporativa diminuem o gerenciamento de resultados? Evidências a partir da aversão na divulgação de prejuízos e de queda nos lucros. Revista Contemporânea de Contabilidade, v. 11, n. 22, p. 141-162, 2014.

RAZZAQUE, R. Md R.; ALI, M. J.; MATHER, P. R. Real earnings management in family firms: Evidence from an emerging economy. Pacific-Basin Finance Journal, v. 40, p. 237-250, 2016.

REZENDE, G. P.; NAKAO, S. H. Gerenciamento de resultados e a relação com o lucro tributável das empresas brasileiras de capital aberto. Revista Universo Contábil, v. 8, n. 1, 2012.

RODRÍGUEZ-PÉREZ, G.; VAN HEMMEN, S. Debt, diversification and earnings management. Journal of accounting and public policy, v. 29, n. 2, p. 138-159, 2010.

ROSA, R. C.; TIRAS, S. L. Adoção do IFRS no Brasil: um terreno fértil para pesquisa sobre gerenciamento de resultados. BBR-Brazilian Business Review, v. 10, n. 4, p. $141-156,2013$.

SHAYAN-NIA, M.; SINNADURAI, P.; MOHD-SANUSI, Z.; HERMAWAN, A. A. How efficient ownership structure monitors income manipulation? Evidence of real earnings management among Malaysian firms. Research in International Business and Finance, v. 41, p. 54-66, 2017.
SILVA, Pedro Y. C.; FONSECA, Marcos W. Gerenciamento de resultados: estudo empírico em empresas brasileiras e portuguesas antes e após a adoção das IFRS. Base, v. 12, n. 3, 2015.

SILVA, A.; PLETSCH, C. S.; VARGAS, A. J.; FASOLIN, L. B.; KLANN, R. C. Influência da auditoria sobre o gerenciamento de resultados. Revista de Contabilidade do Mestrado em Ciências Contábeis da UERJ, v. 19, n. 3, p. 59-69, 2014.

SOBRINHO, W. B. R.; RODRIGUES, H. S.; OLIVEIRA, I. G. S.; ALMEIDA, J. E. S. A Competição do mercado, Impacto nos componentes do lucro contábil e no retorno das ações. Revista Gestão Finanças e Contabilidade, v.4, n.2, p.54-72, 2014.

SCHIPPER, K. Earnings management. Accounting Horizons, v. 3, n. 1, p. 91-102, 1989.

VLADU, A. B.; CUZDRIOREAN, D. D. Detecting earnings management: Insights from the last decade leading journals published research. Procedia Economics and Finance, v. 15, p. 695-703, 2014.

XUE, S.; HONG, Y. Earnings management, corporate governance and expense stickiness. China Journal of Accounting Research, v. 9, n. 1, p. 41-58, 2016.

WEI, Z.; WU, S.; LI, C.; CHEN, W. Family control, institutional environment and cash dividend policy: evidence from China. China Journal of Accounting Research, v. 4, n. 1-2, p. 29-46, jun. 2011.

WOODWARD, J. Industrial Organization: Theory and practice. Londres. Oxford University Press, 1965. 